\title{
Evaluation of thermodynamic properties for the biosorption of chromium by using cherry leaves (Muntingia calabura L.)
}

\author{
R. Aathithya, J. Rajani Sowparnika, V. Balakrishnan* \\ Department of Biotechnology, K. S. Rangasamy College of Technology, \\ Tiruchengode - 637 215, Tamil Nadu, India \\ *E-mail address: palanivbalu@gmail.com
}

\begin{abstract}
Chromium is a heavy metal which has widely used in tannery and electroplating industries. Contaminations of these industrial metals into the river possess major threat to an environment. Therefore, biosorption is a technique which is applied for the sorption of heavy metal by a biomaterial. In the present study reveals that cherry leaves was used as a biomaterial and for that the thermodynamic properties was evaluated for the biosorption of chromium. From the thermodynamic studies it was found that the reaction was feasible, spontaneous and exothermic because the values of $\Delta \mathrm{G}=$ negative, $\Delta \mathrm{S}=$ negative and $\Delta \mathrm{H}=$ positive. So, it was concluded that the experiment was thermodynamically feasible.
\end{abstract}

Keywords: Chromium; Thermodynamic study; Free energy; Entropy

\section{INTRODUCTION}

Direct disposal of waste into environments such as natural waterways causes waste to build up within the water. A pungent odor is the final result. Additionally, such type of waste decreases the amount of available oxygen in water and causing the death of aquatic animals or other organisms. It is a hard metal of steely gray color and also it has a high melting point of $1907{ }^{\circ} \mathrm{C}$. It is odorless and tasteless metal. Many of it compounds are intensely colored. Chromium is an important metal due to its high corrosion resistance and hardness. This metal is of major concern because of their larger usages in developing countries and their non degradability nature (Shankar et al., 2006). The discharge of effluents from these industries constitutes one of the major causes of land and water pollution by the addition of chromium compounds. Chromium degradation can be possible with the help of variety of bacterial and fungal groups like Arthrobacter sp. and Bacillus sp., (Megharaj et al., 2003) E. coli ATCC 33456 (Bae et al., 2000 and Shen and Wang, 1994), Pseudomonas aeruginosa (Aguilera et al., 2004), Brevebacterium casei (Alok and Susmitha, 2010), Acinetobacter sp (Srivastava and Indu, 2006) some unidentified species like Pseudomonas fluorescens, Pseudomonas synxantha (Gopalan and Veeramani, 1994; McLean and Beveridge, 2001) Alcaligenes eutrophus (Vaneechoutte et al., 2004). 


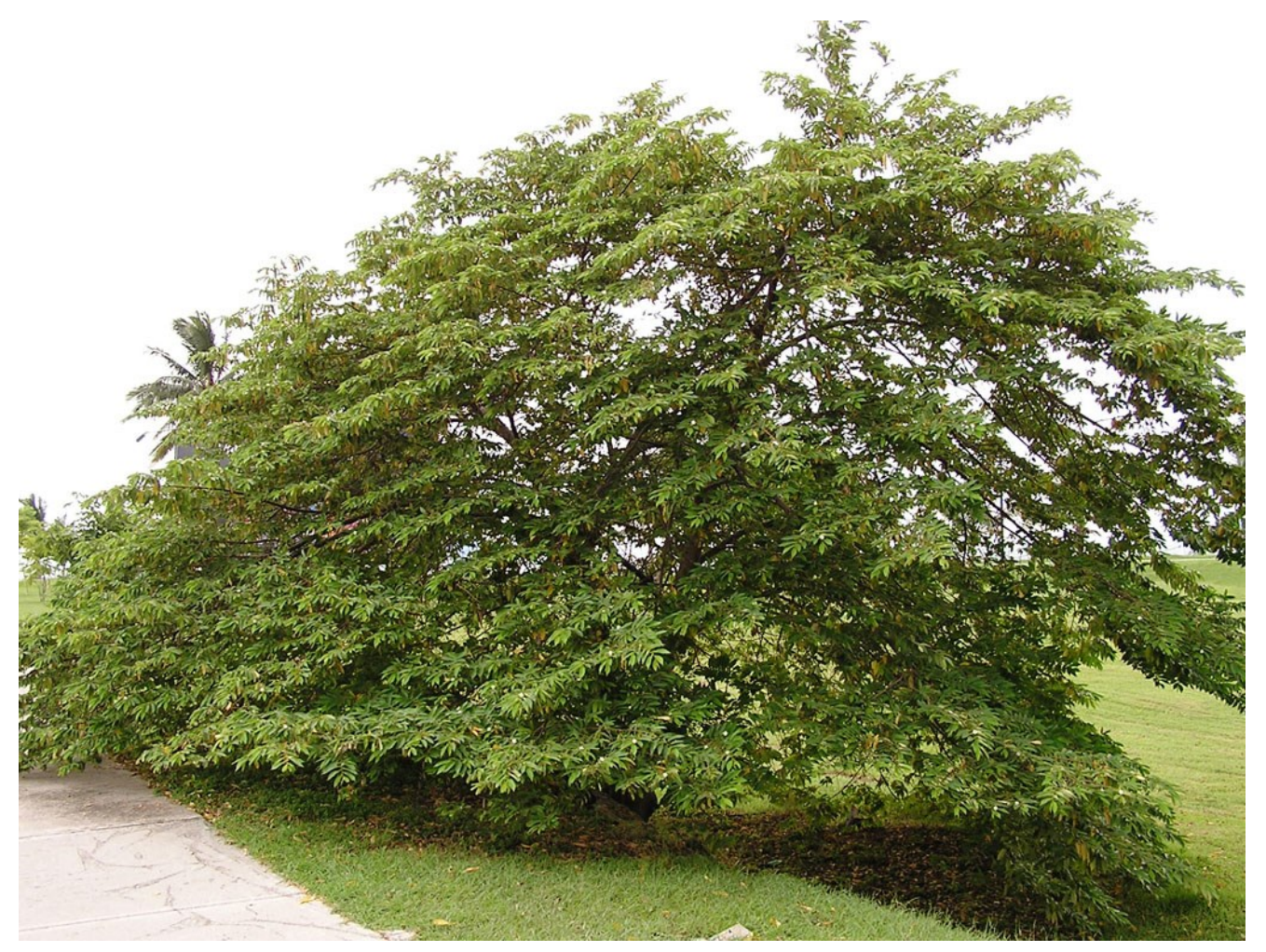

Photo 1. Muntingia calabura - tree.

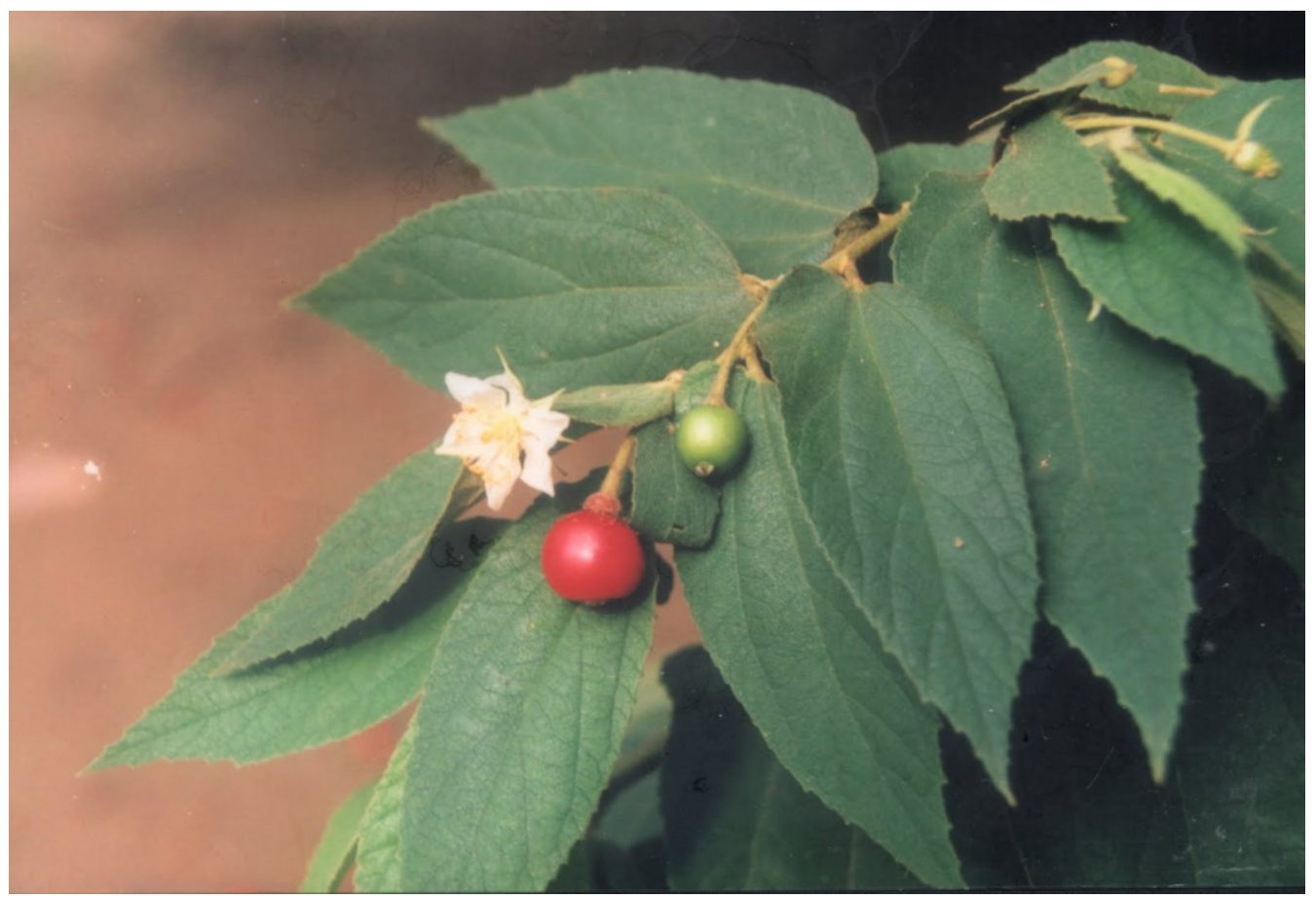

Photo 2. Muntingia calabura - flower and fruit.

Deepa Prabhu et al. (2006) stated that biosorption is an emerging and attractive technology that involves sorption of dissolved substances by a biomaterial. It is a potential 
technique for the removal of heavy metals from solutions and recovery of precious metals. In this present work thermodynamic properties were studied for the biosorption of chromium using cherry leaves.

\section{MATERIALS AND METHODS}

\section{1. Selection of the plant}

Cherry leaves were selected as an adsorbent for removal of chromium ion in this study. The leaves were obtained from a Cherry tree located in K. S Rangasamy College of Technology (Autonomous), Tiruchengode. The plant was identified and authenticated by Botanical Survey of India Southern Circle,Tamil Nadu Agricultural University, Coimbatore. The binomial name of cherry leaves is Muntingia calabura L.

\section{2. Preparation of leaf adsorbent}

Mature Cherry leaves were collected and it was washed thoroughly under running tap water to remove dust and any adhering particles. The leaves were then dried under sunlight for a few days until it became crisp. The dried leaves were crushed and blended to powder form using a blender. It was stored in an airtight plastic for further use to avoid contact with moisture in atmosphere.

\section{3. Preparation of chromium stock solution}

Stock solution of chromium of $1000 \mathrm{mg} / \mathrm{L}$ was prepared by dissolving $2.828 \mathrm{~g}$ of potassium dichromate in $1 \mathrm{~L}$ of distilled water. The working solution was prepared by diluting the stock solution.

\section{4. Chromium analysis}

Chromium content was analyzed by using spectrophotometric method, as described in the Standard methods for the Examination of Waste and Wastewater (APHA), to measure the concentrations of the $\mathrm{Cr}$. The reaction takes place between $\mathrm{Cr}$ and 1,5-diphenycarbazide results in the pink coloured complex. Then it was able to be spectrophotometrically analyzed at $540 \mathrm{~nm}$.

\section{5. Evaluation of thermodynamics parameters}

Thermodynamic parameters such as $\Delta \mathrm{G}, \Delta \mathrm{H}, \Delta \mathrm{S}$ were calculated at constant temperature using the equation such as,

$$
\Delta \mathbf{G}=-\mathbf{R T} \log \mathbf{K}, \Delta \mathbf{G}=\Delta \mathbf{H}-\mathbf{T} \Delta \mathbf{S}
$$

where,

$\mathrm{K}=\mathrm{q}_{\mathrm{e}} / \mathrm{c}_{\mathrm{e}}, \mathrm{q}_{\mathrm{e}}=$ Metal uptake at equilibrium $\left(\mathrm{mg} \cdot \mathrm{l}^{-1}\right), \mathrm{c}_{\mathrm{e}}=$ Concentration of metal ion at equilibrium $\left(\mathrm{g} \cdot \mathrm{l}^{-1}\right), \mathrm{R}=$ Gas constant, $\mathrm{T}=$ Absolute temperature in $\mathrm{K}, \Delta \mathrm{S}=$ Entropy, $\Delta \mathrm{H}=$ enthalpy, From the plot of $\log \mathrm{K}$ vs $1 / \mathrm{T}$, the slope and intercept tends to entropy and enthalpy.

Pearson's chi-squared test was used to analyze the goodness of fit for pseudo first and second order reactions model. Its properties were first investigated by Karl Pearson in 1900 . 


\section{RESULTS AND DISCUSSION}

\section{1. Evaluation of thermodynamic parameters}

Fig. 1 shows that the plot of $\mathrm{K}$ vs $\Delta \mathrm{G}$ at different concentration of chromium from the graph the thermodynamic parameters were determined from the slope and intercept values as $\Delta \mathrm{H}$ and $\Delta \mathrm{S}$. Free energy was calculated to determine the nature of the reaction whether it is feasible or not. The negative value of $\Delta \mathrm{G}$ indicates the feasibility of the reaction and the spontaneous nature of sorption. $\Delta \mathrm{H}$ is the measure of total energy of the system. The negative value of $\Delta \mathrm{H}$ denotes that the reaction is exothermic in nature. Entropy $(\Delta \mathrm{s})$ was found to be positive this indicates the spontaneous nature of reaction.

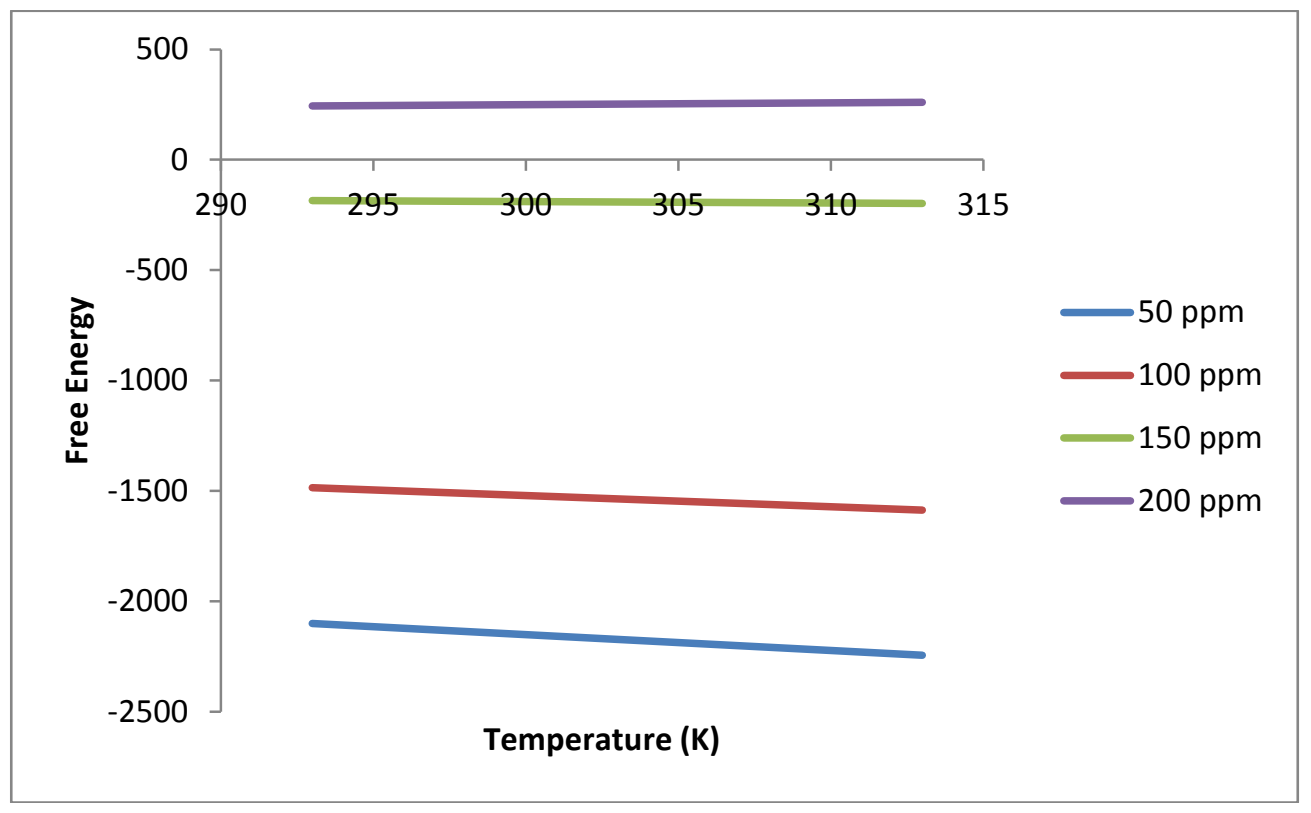

Fig. 1. Plots of $K$ vs $\Delta G$ for the adsorption of chromium at different concentrations.

Table 1. Thermodynamic Properties for the Biosorption of Chromium at Different Concentrations Biosorbent Dosage $0.5 \mathrm{~g} / \mathrm{l}$ ).

\begin{tabular}{|c|c|c|c|c|c|}
\hline \multirow{2}{*}{$\begin{array}{l}\text { Co } \\
\text { g/l }\end{array}$} & \multirow{2}{*}{$\begin{array}{c}\Delta \mathbf{H} \\
\mathbf{K J} / \mathbf{m o l}\end{array}$} & \multirow{2}{*}{$\begin{array}{c}\Delta S \\
\mathbf{K J} / \mathbf{m o l ~ K}\end{array}$} & \multicolumn{3}{|c|}{$\begin{array}{c}\Delta \mathbf{G} \\
\mathbf{K J} / \mathbf{m o l}\end{array}$} \\
\hline & & & $293 \mathrm{~K}$ & $303 \mathrm{~K}$ & $313 \mathrm{~K}$ \\
\hline 0.05 & -7.185 & 4.115 & -2101 & -2173 & -2244 \\
\hline 0.1 & -5.073 & 0.236 & -1485 & -1536 & -1587.34 \\
\hline 0.15 & -0.046 & 4.282 & -185.13 & -191.45 & -198.056 \\
\hline 0.2 & 0.83 & 0.41 & 243.6 & 251.9 & 260.28 \\
\hline Mean & -3.0175 & 2.2611 & -881.875 & -912.262 & -941.529 \\
\hline
\end{tabular}




\section{CONCLUSION}

From the thermodynamic studies it was found that the reaction was feasible, spontaneous and exothermic because the values of $\Delta \mathrm{G}=$ negative, $\Delta \mathrm{S}=$ negative and $\Delta \mathrm{H}=$ positive. So, it was concluded that the experiment was thermodynamically feasible.

\section{Acknowledgement}

The authors are gratefully acknowledge the Management, Principal, Professor \& Head, Department of biotechnology, K. S. Rangasamy College of Technology, for providing laboratory facilities to carry out the work successfully.

\section{References}

[1] Aguilera S., Aguilar M.E., Chavez M.P., Lopez-Meza J.E., Pedraza-Reyes M., Campos Garcia J., Cervantes C., FEMS Microbiology Letters (2004) 107-112.

[2] Alok P., Susmitha M., Journal of Carcinogenesis (2010) 6-10.

[3] Bae W., Gu K., Kang I., Won Y., Jeong C., Journal of Microbiology (2000) 36-39.

[4] Deepa Prabhu M., Thiruvenkatachari V., Yee-Chung J., Journal of Physicochem. Eng. Aspects. 301 (2006) 214-223.

[5] Gopalan R.,Veeramani H., Journal of Biotechnology and Bioengineering 43 (1994) 471-476.

[6] McLean J., Beveridge T., Journal of Applied Environment Microbiology 67 (2001) 1076-1084.

[7] Megharaj M., Avudainayagam S., Naidu R., Journal of Current Microbiology 47 (2001) 51-54.

[8] Shankar C., Sridevi D., Joonhong P., Michael D., Thamaraiselvi K., Journal of Hazardous Materials 146 (2006)270-277.

[9] Shen H., Wang Y., Journal of Environmental Engineering 120(3) (1994).

[10] Srivastava S., Indu S., Journal of Bioresource Technology 97 (2006) 1167-1173.

[11] Standard Methods for the Examination of Water and Wastewater, American Public Health Association, Washington, DC, USA. (1998) $20^{\text {th }}$ edition.

[12] Vaneechoutte M., Kampfer P., Baere T.D., Falsen E., Verschraegen G., International Journal of Systematic and Evolutionary Microbiology 54(180) (2004)317-327. 